\title{
Restaurando a saúde mental na Índia. Terapias e conceitos pluralísticos
}

SÉBASTIA, B.

Restoring mental health in India. Pluralistic therapies and concepts.

New Delhi: Oxford University Press, 2009.

| ${ }^{1}$ Pamela Siegel, ${ }^{2}$ Nelson Filice de Barros |

${ }^{1}$ Universidade Estadual de Campinas. Endereço eletrônico: pamsky@mpc.com.br

${ }^{2}$ Universidade Estadual de Campinas. Endereço eletrônico: nelfel@uol.com.br

Brigitte Sébastia é pesquisadora na área de antropologia social do Institute of Pondicherry e membro associado do Centre d'Anthropologie Sociale, Université Toulouse Le Mirail, Toulouse, e do Centre d'Études de L'Inde et de L'Asie du Sud, Paris. O livro por ela organizado tem 324 páginas e contem dez artigos de diferentes autores, com múltiplas abordagens da saúde mental, divididos em três partes, de acordo com os seguintes eixos temáticos: as medicinas indianas codificadas, a terapia popular e a psiquiatria.

No capítulo primeiro, intitulado "Medical, literate, and cultural approaches to mental disorders in Tamil Nadu", Somasundaram faz incursōes na sociedade Tamil, buscando as descrições da saúde mental. Esta cultura desenvolveu o sistema médico Siddha, que floresceu no sul da Índia e remontaria ao deus Shiva de quem os santos, yogues e eruditos teriam herdado a tradição do preparo de medicamentos com ervas, venenos e metais. Entre os eruditos, o autor cita Tirumular, cuja contribuição foi o estudo do yoga e da meditação no tratamento das doenças humanas.

No sistema Siddha, os três humores (vali, alal e ayam) representam a criação, proteção e destruição, relacionados às funções anabólica, metabólica e catabólica do organismo, sendo a prevalência de alal - a temperatura do corpo, que representa as atividades metabólicas tais como a absorção, a assimilação e a termogênese considerada pelos sábios uma das causas da doença mental, juntamente com outras variáveis como variação sazonal, hábitos dietéticos, idade e sexo do indivíduo. 
Por fim, Somasundaram explica que o sistema Siddha de medicina classifica as variedades clínicas da doença mental de acordo com a sintomatologia, e a obra de Akattiyar lista 18 variedades de psicoses funcionais e os respectivos tratamentos usados: fumigação, massagem, aplicações nasais, oculares e psicoterapia.

No capítulo dois, "Dosa, Satvabalam, Genes, and Puja: a god for everything. An ethnographic study of a government ayurvedic mental hospital", a autora Nadia Giguère explora a multiplicidade de discursos e práticas sobre saúde mental encontrados em Kerala. A obra Astangahrdaya Sambita, composta entre os séculos VI e VII, é a mais usada no Government Ayurvedic Mental Hospital (GAMH) e nela constam que problemas mentais específicos aparecem quando os canais por onde fluem os humores e os elementos em direção ao coração não funcionam eficientemente. Mas existe outro nível etiológico no sistema ayurvédico, que é nidana, uma conjunção de fatores que inclui tensões, tristeza, dieta, etc., e que, segundo os profissionais de saúde do GAMH, estaria na raiz da doença. O êxito no tratamento depende de quatro fatores: o médico, o medicamento (remédio ou dieta), o cuidado e certas características do paciente, daí o surgimento de negociaçóes médico-paciente, e muitos discursos que vão além da recuperação das funções corporais, abrindo diferentes perspectivas sociais, culturais e metafísicas da doença, que permitem ao paciente escolher a identidade da doença com a qual mais se identifica.

O capítulo terceiro, intitulado "The Relevance of yoga and meditation in the management of common mental disorders", é escrito por C. Kumar Babu, psiquiatra indiano que ensinou yoga e meditação em Chennai por 15 anos. O autor afirma que mesmo com um diagnóstico precoce, o manejo dos transtornos mentais comuns (TMCs) apresenta muitos problemas. Os medicamentos para tratar estas condições causam severos efeitos iatrogênicos em 30\% dos casos e, para aqueles pacientes que respondem bem a eles, o custo pode ser proibitivo. Portanto, existe uma população numerosa que sofre de TMCs, mas não pode ser ajudada pela terapia das drogas e precisa procurar intervenções não-farmacológicas.

Babu faz uma revisão da literatura e se concentra principalmente nos textos de Grover (1994), que estuda os trabalhos realizados nos anos 1970, e Kirkwood et al. (2005), que analisam os estudos mais recentes, da década de 1990. O autor afirma que existe evidência preliminar para mostrar que o yoga e a meditação podem ser efetivos no manejo dos TMCs, mas admite que há metodologias deficientes nos estudos analisados e que há a necessidade de uma padronização da yogaterapia. 
O capítulo quarto, "When God heals... can Darsan be a therapy?", escrito por Pilar Galiana Abal, aborda trabalhos de campo, mais especificamente entrevistas feitas no templo de Babulnath, em Mumbai, com devotos da veneração ao Shiva linga. A performance do darsan é um movimento religioso baseado na devoção e consiste de atitudes teatrais que têm um significado simbólico-cultural, incluindo mantras, oferendas de flores, água e leite à deidade, bem como contato físico com a mesma. A autora descreve os passos do ritual: regar a imagem de Shiva linga com leite, ajoelhar-se diante da imagem, beijá-la, conversar com ela, deitar-se na frente dela, meditar diante dela, etc. E o fato de o símbolo do Shiva linga ter o formato de um falo ainda acrescenta outros significados simbólicos, já que o linga (falo) emerge de um yoni (vulva), ambos representando a união dos princípios masculino/feminino da energia divina.

A autora sugere que o Shiva linga poderia representar o peito materno na psique hindu e conclui que o ritual todo representa o retorno ao útero materno. Segundo a autora, ocorrendo uma "transferência" para um objeto não humano, de veneração, pode haver melhoria da saúde mental das pessoas a partir destas práticas religiosas regulares; ela acredita que através das performances espirituais uma forma de transferência é possível, abrindo um caminho para a elaboração psíquica.

Marine Carrin é a autora do quinto capítulo, intitulado "Women's Agency Recasting Distress in Two Therapeutic Cults of India (Bengal and Karnataka)", que trata de compreender como o afeto e a emoção, nas suas dimensões culturais, se manifestam em dois cultos de possessão em duas regiōes da Índia. A maioria dos possuídos são mulheres cuja possibilidade de expressão lhes foi negada e um dos aspectos mais interessantes da possessão é a forma como ela renegocia a distinção entre o si-mesmo e o outro. O sofrimento feminino é entendido como a possessão de um espírito, já que seus corpos são vistos como passíveis de serem possuídos por um espírito. Na região de Bengal, a possessão feminina não é considerada como uma expressão própria da devoção e, como não é permitida para mulheres, é interpretada como uma experiência religiosa excepcional, como sendo o chamado da deusa Kali. Embora alguns psiquiatras critiquem estes altares de cura, dizendo que são "tratamento placebo", a autora considera que há um precioso alívio nesses lugares quando se considera a falta de terapias adequadas às classes subalternas.

A autora menciona o culto Siri, praticado na sociedade matrilinear em Kanara do sul, que é um ritual terapêutico que ativa a memória episódica, por meio de um 
diálogo entre devotos, que permite às mulheres esquecerem a própria identidade e projetarem-se na família Siri. A autora indaga se o efeito do ritual é realmente terapêutico e sugere que não podemos assumir que as mulheres estejam curadas, mas que sua possessão indesejada é transformada num papel ritual.

No capítulo seis, "Mythologizing distress possession and therapy in Balaji Mehendipur (Rajasthan)", Florence Halder apresenta um estudo antropológico conduzido em 2006 em três altares terapêuticos de diferentes fés: hindu, jainista e sufi, que são especializados em tratar pessoas possuídas por espíritos malévolos, mas ela se concentra mais no templo de Balaji.

A forma em que o estresse é manifestado através da possessão depende do sistema terapêutico de cura encontrado, segundo autores das áreas de antropologia, etnopsiquiatria e psicanálise, a tentativa de identificar os espíritos maléficos e as formas de se livrar deles depende da maneira como os possuídos chegam ao lugar, o tempo de permanência e a troca de experiências com outros sujeitos possuídos. A maioria dos indivíduos que a autora contatou no templo da Balaji havia visitado um médico antes e recebido o diagnóstico de que não havia nada de errado com seu corpo. As queixas variavam entre dores de cabeça ou em várias partes do corpo, no estômago ou nas costas; insônia e perda de apetite.

$\mathrm{O}$ transe dura até o momento em que a entidade revela sua identidade. Um ritual é celebrado de manhã e à noite, na frente da estátua de Balaji e tem como função facilitar a interação entre a deidade e seus devotos. Música acompanha o ritual e socializa o transe. Ali se usa a projeção e a sublimação dos efeitos, dança, convulsões, terapias individuais e grupais, amuletos, mas também são usadas as antigas terapias para expulsão dos espíritos, tais como a repetição de mantras, rituais, oferendas, oraçôes, sugestôes autoritárias, penitência e atividades devocionais, havendo grande variedade de exorcistas.

Brigitte Sébastia, a organizadora do livro, é também a autora do sétimo capítulo, intitulado "The last resort why patients with severe mental disorders go to therapeutic Shrines in India”. A autora relata que a hospitalização dos doentes mentais começou nos séculos XI e X nas cidades islâmicas de Bagdá, Cairo, Fez e Damasco, espalhando-se durante o século XIV aos países sob o domínio islâmico, como a Espanha e a Índia, onde os hospitais foram estabelecidos por questôes de caridade. No entanto, antes da existência dos hospitais, existia um sistema de hospitalização em templos e em casas de curandeiros. Este tipo de 
duplo tratamento, que combina religião e medicina continua a ser oferecido em alguns templos, bem como por alguns feiticeiros, astrólogos, padres, exorcistas e, em Tamil Nadu, por praticantes da medicina Siddha.

O santuário católico de Puliyampatti está dedicado a Santo Antônio de Pádua e recebe pacientes bipolares, esquizofrênicos, depressivos, além de pacientes com câncer, malformação cardíaca e degeneração motora. As condições de moradia no santuário de Puliyampatti são rudimentares e desconfortáveis, mas a coexistência das famílias que compartilham o mesmo tipo de sofrimento e que são vítimas de semelhante estigmatização torna a situação aceitável. A autora afirma que ela raramente pode constatar uma melhoria dos doentes mentais graves. Há crises reincidentes, muito embora existam períodos de calma. De acordo com ela, o ambiente de apoio do santuário favorece, sobretudo, os parentes destes pacientes.

A história dos asilos na Índia proporciona uma oportunidade de estudar uma gama de idéias sobre doença mental e as noçôes do cuidado e da responsabilidade através das culturas e do tempo. É deste tema que trata o capítulo oito, "Diagnosis and treatment approaches at the asylum in Bangalore", dos autores Pratima Murthy and Sanjeev Jain. Os hospitais e o aparato administrativo moderno do cuidado em saúde se espalharam através do mundo desde suas origens no Oriente Médio no primeiro milênio. Entre 1500 e 1750, houve um incremento de conscientização sobre a medicina européia e um diálogo com as medicinas galênicas, ayurvédicas e unani; o uso de sanguessugas, ventosas, purgativos e metais era amplamente praticado.

O diário do Dr. Charles Smith e de seu filho, registrando suas experiências no asilo de Bangalore, por volta de 1847, proporciona uma gama de detalhes sobre a medicina ocidental da época. Ali, enfatizava-se o trabalho com atividades como jardinagem, tecelagem com corda e trabalhos domésticos, sendo que sua população de internados consistia de armênios, católicos europeus, italianos, irlandeses, ingleses e indianos do país inteiro. Álcool e ganja (cannabis) estavam listadas como causas físicas comuns de insanidade. Passaram a existir unidades psiquiátricas em todos os hospitais e somente os casos crônicos deveriam ser tratados em hospitais psiquiátricos.

Em 1974, após várias reformulações, o asilo de Bangalore foi renomeado como National Institute of Mental Health and Neurosciences. A autora fez ali um estudo com uma amostra de 76 prontuários de pacientes, admitidos em Bangalore em 
períodos diferentes. As teorias psicanalíticas foram encaradas como sendo muito simplistas e prematuras na sua tentativa de identificar causas, daí que maior importância foi atribuída à abordagem fenomenológica. Este ceticismo sobre a psicoterapia ocidental pode explicar porque as idéias freudianas não conseguiram se sedimentar na psiquiatria formal na Índia.

O nono capítulo, intitulado "Symbolic efficacy in the therapeutic theatre. Girindrasekhar Bose's Re-elaboration of the psychoanalytical corpus", de Jean Nimylowycz, relata a paixão de Bose pela magia e pela hipnose muito antes da publicação de Freud e Breuer, Studies on Hysteria. Mais tarde, ele se dedicará ao estudo dos Yoga Sutras de Patanjali. A principal indagação de Bose girava em torno de como os intelectuais indianos poderiam dialogar com as abordagens positivistas-racionalistas e o dharma.

Esse diálogo acabou gerando um modelo híbrido, com elementos de ambas as culturas, ocidental e oriental, e Bose acabou criando uma técnica de cura original, que é uma síntese de teoria primordial freudiana e o yoga. A diferença básica é que Bose considerava o desejo como uma reação funcional a um estímulo externo, enquanto que para Freud o instinto é a representação psíquica de uma excitação interna. O ego, para Bose, seria uma mônada psíquica, um reservatório de desejos tanto conscientes como inconscientes, incluindo o ego freudiano, o id e o superego, além de elementos contraditórios. Ele se deu conta de que no momento em que o material originalmente reprimido se tornava consciente, um material de tipo oposto, previamente consciente, se tornava reprimido e imediatamente substituía o seu oposto no inconsciente, ou seja, as resistências e os sintomas mantinham sua ação. Depois, enquanto a cura estava em curso, os conteúdos reprimidos e conscientes se invertiam novamente até que ambos fossem reconhecidos pelo paciente, é aí que o sintoma desparecia.

Bose combinava a influência freudiana com o modelo terapêutico inspirado na tradição mestre-discípulo. A parte yoguica envolvia a visualização para se identificar com a deidade, com o intuito de despertar o divino em si mesmo, processo que fazia emergir as representações que ele deveria aprender a controlar. Contudo, o problema que ambos, Bose e seus pacientes, tinham que enfrentar, era estar na fronteira de ambas as perspectivas: a europeia e a hindu, mantendo uma relação crítica tanto com o dharma como com o racionalismo. 
O décimo capítulo, intitulado "Gender blind or gender biased? Culture, family, and patriarchy in Indian psychiatry", de autoria de Renu Addlakha, examina os papéis de gênero na teoria e na prática psiquiátrica, através de uma revisão de literatura e do trabalho clínico, sendo parte de um estudo etnográfico maior sobre a prática psiquiátrica desenvolvida na unidade psiquiátrica do Lady Hardinge Medical College and Hospital (LHMCH) em Delhi, que começou a funcionar como uma unidade independente em maio de 1982.

$\mathrm{O}$ autor enfocou sua busca nos diferentes critérios de anormalidade e na interface entre cultura e personalidade, com referências específicas à etiologia, definição e tratamento de transtornos mentais entre mulheres indianas. Três perspectivas podem ser usadas para examinar a relação entre mulheres e doença mental: a primeira diz respeito aos dados epidemiológicos; a segunda se refere à forma em que o patriarcado impacta a saúde mental das mulheres, e a terceira abrange a crítica feminista ao conhecimento, a qual alega que disciplinas tais como a psicologia e a psiquiatria são falocêntricas.

O trabalho com vítimas de diferentes traumas permite identificar que há profundas semelhanças entre sofredores de neurose de combate, como em soldados, e vítimas de violência sexual e doméstica. A síndrome da mulher maltratada (battered woman syndrome) foi oficialmente reconhecida como uma subcategoria da síndrome de depressão pós-traumática no DSM IV, pela Associação Psiquiátrica Americana, em 1994. E estudos mostram que há uma maior utilização de terapia religiosa, como as curas nos templos, exorcismo e curas pela fé entre as mulheres. O autor cita os estudos de feministas como Elaine Showalter, Inge K. Broverman, Carol Gilligan, Sandra Harding e Evelyn Fox Keller que, no geral, concordam com o fato de não existirem discursos objetivos e universais operando isoladamente das instituições e ideologias patriarcais. Enquanto que o sexo tem sido uma variável constante nos estudos epidemiológicos, o gênero, que como o sexo é configurado pela cultura e sociedade, é bastante ausente.

No pósfacio, os autores Gilles Bibeau e Ellen Corin situam a saúde mental na interface entre os textos clássicos indianos, as práticas religiosas e o conhecimento psiquiátrico moderno, e admitem que o maior desafio para o povo indiano é sintetizar os valores tradicionais e modernos, o darshan filosófico com a construção de um país liberal, mais sensível à equidade e igualdade, e sustentado, pelo menos 
em parte, pelo espírito de solidariedade e inclusividade que o Mahatma Gandhi implantou no coração da democracia indiana.

Mantendo as devidas proporçôes, há semelhanças entre a forma em que tanto a religiosidade indiana como a brasileira interpenetram o campo da saúde mental. No Brasil, a matriz religiosa africana atua com o Candomblé, a Umbanda, a Pajelança e a Jurema, sendo o transe mediúnico a forma de canalizar a busca pela cura. Encontramos evidências, também, de que o envolvimento religioso/ espiritual pode influenciar positivamente o cuidado com a saúde, estimulando a abstinência, redução ou abandono do uso de drogas e, além disso, aumentar o bem-estar psicológico e diminuir a depressão, os pensamentos e comportamentos suicidas, sendo o impacto positivo mais intenso entre os idosos e indivíduos com deficiências e doenças clínicas.

Enfim, o livro é uma importante referência para profissionais da área da saúde e acadêmicos que estudam tanto saúde mental quanto cultura e práticas complementares e integrativas, pois é composto de uma coletânea de artigos muito bem elaborados, escritos por especialistas em antropologia médica e social, psiquiatria e psicologia, pertencentes a instituições acadêmicas francesas, indianas, canadenses e norte-americanas.

\section{Referências}

ABDALA, G.A.; RODRIGUES, W.G.; TORRES, A. et al. A religiosidade / espiritualidade como influência positiva na abstinência, redução e/ou abandono do uso de drogas. Revista de Estudos da Religiāo, São Paulo, março, p. 77-98, 2010.

CARVALHO, J.J. de. Uma visão antropológica do esoterismo e uma visão esotérica da antropologia. Série Antropologia, Brasília, n. 406, p. 2-23, 2006.

HENNING, M.C.; MORÉ, C.L.O.O. Religião e psicologia: análise das interfaces temáticas. Revista de Estudos da Religião, São Paulo, p. 84-114, dez.2009. 